Pesq. Vet. Bras. 37(3):269-277, março 2017 DOI: $10.1590 /$ S0100-736X2017000300011

\title{
Morfologia comparada do aparelho respiratório de capivaras (Hydrochoerus hydrochoeris) $^{1}$
}

\author{
Amanda O. Moreto $^{2}$, Franceliusa D. Oliveira ${ }^{2}$, Bruno M. Bertassoli ${ }^{2}$ \\ e Antônio C. Assis Neto ${ }^{2 *}$
}

\begin{abstract}
Oliveira F.D., Moreto A.O., Bertassoli B.M. \& Assis Neto A.C. 2017. [Comparative morphology of the respiratory organs of capybaras (Hydrochoerus hydrochoeris).] Morfologia comparada do aparelho respiratório de capivaras (Hydrochoerus hydrochoeris). Pesquisa Veterinária Brasileira 36(3):269-277. Departamento de Cirurgia, Faculdade de Medicina Veterinária e Zootecnia, Universidade de São Paulo, Av. Prof. Dr. Orlando Marques de Paiva 87, Butantã, Cidade Universitária, São Paulo, SP 05508-270, Brazil. E-mail: antonioassis@usp.br

The capybara, a wild rodent typical of the South American continent, is a source of food in all regions of its occurrence and is an important component in the diet of indigenous people and the rural population of Brazil. Knowledge of morphology is basic for the biological management of wild animals. Due to the scarcity of literature on morphological and anatomical studies of the respiratory tract of capybara, the aim of this study is to analyze the organs of this apparatus, macro and microscopically, so we can acquire better basic knowledge and compare it with that of animals of the same suborder (Histricomorpha) and with other species of mammals. We have seen that the respiratory tract of capybara is formed through the nostrils, nasal, nasal cavity, paranasal sinuses, phisarynx, larynx, trachea and lungs. The nose is located in nasal plan with nostrils arranged laterally. The largest part of the nasal cavity of the capybara is occupied by the turbinates, which performe as spiral-shaped structures, with their respective meati. The larynx is bounded by cartilage and in communication with the trachea. The trachea is a flexible cartilaginous and membranous tube, with incomplete rings in the shape of a "C", which is bifurcated in its terminal part, forming the tracheal carina. The lungs of capybaras are in pairs, right (with four lobes) and left (with two lobes), located in the chest cavity. The bronchial tree of capybara is formed by primary bronchi and by a sequence that includes intrapulmonary bronchi, bronchioles, terminal bronchioles, and respiratory bronchioles.
\end{abstract}

INDEX TERMS: Capybara, Hydrochoerus hydrochoeris, rodents, anatomy, histology, respiratory tract.

RESUMO.- A capivara (Hydrochoerus hydrochoeris), um roedor silvestre típico no continente Sul-americano, é utilizada como fonte de alimento em toda a sua região de ocorrência, sendo um importante componente na dieta de povo indígena e população rural do Brasil. 0 conhecimento da morfologia fornece bases para outras áreas de atuação, bem coamo, para o manejo biológico de animais silvestres. Devido à escassez na literatura de estudos anatômicos e mor-

\footnotetext{
${ }^{1}$ Recebido em 23 de maio de 2015.

Aceito para publicação em 21 de fevereiro de 2016.

2 Departamento de Cirurgia da Faculdade de Medicina Veterinária e Zootecnia (FMVZ), Universidade de São Paulo (USP), Av. Prof. Dr. Orlando Marques de Paiva 87, Cidade Universitária, São Paulo, SP 05508-270, Brasil. E-mails: delys@usp.br, amandamoreto@gmail.com, brunobertassoli@ gmail.com; *Autor para correspondência: antonioassis@usp.br
}

fológicos do aparelho respiratório da capivara, o objetivo deste trabalho é analisar os órgãos deste aparelho, macro e microscopicamente, para que possamos adquirir melhor conhecimento básico e compará-lo com o de animais da mesma subordem (Histricomorfos) e com outras espécies de mamíferos. Vimos que o aparelho respiratório da capivara é formado pelas narinas, fossas nasais, cavidade nasal, seios paranasais, faringe, laringe, traqueia e pulmões. 0 nariz se localiza em plano nasal com as narinas dispostas lateralmente. A maior parte da cavidade nasal está ocupada pelas conchas nasais, que se apresentam como estruturas em formato de espiral, com seus respectivos meatos. A laringe está delimitada por suas cartilagens e está em comunicação com a traqueia. A traqueia é um tubo cartilaginoso flexível e membranoso, com anéis incompletos em formato 
de "C", que se bifurca em sua parte terminal, formando a carina traqueal. Os pulmões apresentam-se em pares, direito (com quatro lobos) e esquerdo (com dois lobos), localizados na cavidade torácica. As árvores brônquicas são formadas pelo brônquio primário e por uma sequência intrapulmonar que inclui brônquios intrapulmonares, bronquíolos, bronquíolos terminais e bronquíolos respiratórios.

TERMOS DE INDEXAÇÃO: Capivara, Hydrochoerus hydrochoeris, roedores, anatomia, histologia, trato respiratório.

\section{INTRODUÇÃO}

Há na sociedade contemporânea uma crescente preocupação com a preservação da natureza e, consequentemente, com as diversas formas de vida animal do continente Sul-Americano. Essa preocupação tem sido objeto de estudo em pesquisas tratando de variados animais silvestres da fauna brasileira, tais como cutias (Menezes et al. 2001, Conceição et al. 2008), pacas (Bonatelli et al. 2001, Conceição et al. 2008), capivaras (Reckziegel et al. 2001, Fernandez et al. 2010) e preás (Franciolli et al. 2011).

Os roedores Histricomorfos estão amplamente distribuídos pela América do Sul e África (Luckett \& Mossman 1981). Estes são animais que oferecem uma extraordinária variedade de adaptações ecológicas (Moojen 1962), e morfologicamente, apresentam tamanhos e formato de dentição característica devido ao desprovimento de dentes caninos que, aliados ao aspecto geral da maioria das formas, os tornam facilmente reconhecíveis. Além disto, vivem em diferentes hábitats, podendo expressar diferentes adaptações biológicas (Reig 1984, Conceição et al. 2008).

A capivara, Hydrochoerus hydrochoeris, é o maior roedor atualmente vivo, chegando a medir $1,30 \mathrm{~m}$ de comprimento e 0,50 a $0,60 \mathrm{~m}$ de altura. Pode pesar até $100 \mathrm{~kg}$, com peso médio de $50 \mathrm{~kg}$ para as fêmeas e $60 \mathrm{~kg}$ para os machos. É um herbívoro generalista de hábito semi-aquático, características responsáveis pela origem de seu nome popular "capivara", de origem tupi-guarani, que significa "comedor de capim" (Pereira \& Eston 2007), atinge a maturidade sexual entre 15-18 meses, com peso de aproximadamente 30 kg de massa corpórea, embora os órgãos genitais externos, em ambos os sexos, estejam escondidos por uma prega cutânea (Fernandez et al. 2010). Típico da América Latina possui hábitos normalmente diurnos, com pico de atividades concentrado nos períodos vespertino e crepuscular. 0 ritmo diário de suas atividades resume-se basicamente a forrageio nas primeiras horas da manhã e ao anoitecer e repouso e atividades aquáticas nas horas mais quentes do dia. Os grupos sociais são de tamanhos e composições variáveis dependendo do tipo de ambiente: de grupos com 3 a 14 indivíduos, em média, em áreas pouco alteradas até grupos com mais de 40 indivíduos adultos, em áreas antropizadas (Arouca et al. 2000).

A capivara, como espécie que pertence à fauna sul-americana, há muito é utilizada como fonte de alimento em toda a sua região de ocorrência, sendo um importante componente na dieta de povo indígena e população rural do Brasil (Bressan et al. 2004). Do ponto de vista de saúde pública, os estudos sobre a capivara são de grande impor- tância, já que, por exemplo, a espécie é um dos hospedeiros do carrapato-estrela (Amblyomma cajennense), transmissor da febre maculosa, causada pela bactéria Rickettsia rickettsii. (Pereira \& Eston 2007).

Fernandez et al. (2010) afirma que a criação comercial de capivaras, assim como de algumas outras espécies selvagens, regulamentada pelo Instituto Brasileiro do Meio Ambiente e dos Recursos Naturais Renováveis (IBAMA), pode ser vista como uma promissora atividade geradora de recursos econômicos. Dessa forma, a capivara surge como uma alternativa aos criadores na ocupação racional e sustentável de charcos e banhados, áreas frequentemente não aproveitadas ou de difícil exploração nas atividades pastoris convencionais.

O conhecimento da morfologia fornece bases para a cirurgia, a clínica, a patologia, bem como, para o manejo biológico de animais silvestres. Devido à escassez na literatura de estudos anatômicos e morfológicos do aparelho respiratório da capivara (Hydrochoerus hydrochoeris), nos propomos a estudar e analisar os componentes deste aparelho para que possamos, através de dados obtidos nesta pesquisa, adquirir melhor conhecimento básico e compará-lo com o de animais da mesma subordem (Histricomorfos) e com outras espécies de mamíferos domésticos. Além do mais, informações sobre a Anatomia dos Animais Silvestres da fauna brasileira poderá fornecer informações importantes para a Medicina Veterinária Forense, ainda pouco estudada no Brasil.

\section{MATERIAL E MÉTODOS}

Para a realização desta pesquisa foram utilizadas 3 capivaras, de idade indefinida, provenientes de outros estudos e pesquisas desenvolvidos no Programa de Pós-graduação em Anatomia dos Animais Domésticos e Silvertres da FMVZ-USP (Protocolos do Comitê de Bioética e Experimentação Animal FMVZ/USP no $927 / 2006$ e 241/2002) e já se encontravam fixados em solução de formaldeído a $10 \%$. Portanto, nenhum animal foi submetido a situações de eutanásia, dor e/ou sofrimento. 0 estudo das espécimes foi realizado no Laboratório de Histologia e Embriologia do Departamento de Cirurgia da Faculdade de Medicina Veterinária e Zootecnia da Universidade de São Paulo, SP.

Os animais foram dissecados, retirando-se o conjunto cardiopulmonar, traqueia, laringe e língua, e o material coletado foi fotografado "in situ" e "ex situ". A cabeça dos animais foi cortada logitudinalmente, no plano sargital mediano, para análise macroscópica e remoção de amostras de cada estrutura do sistema respiratório para análise. A fotodocumentação das estruturas foi realizada utilizando-se câmera Sony Mavica 3.2 MP.

As amostras destinadas à histologia foram desidratadas em concentrações crescentes de etanol (70\% a 100\%), diafanizadas em Xilol e impregnadas em parafina Histosec ${ }^{\circledR}$ (Tolosa et al. 2003), para formação de blocos. Os cortes destes foram feitos com $5 \mu \mathrm{m}$ de espessura, em micrótomo Leica RM2125RT, e corados por HE (Hematoxilina/Eosina), Picrossirius e Tricrômio de Masson. Em seguida as lâminas foram montadas com lamínula, utilizando-se Entelan ${ }^{\circledR}$-Merck, e todo o material analisado foi submetido à fotodocumentação em microscópio de luz Olympus DP71, com uso do programa Olympus DP Controller.

A nomenclatura macroscópica utilizada será referida conforme International Committee on Veterinary Gross Anatomical Nomenclature (2012). 


\section{RESULTADOS}

\section{Nariz}

Nas capivaras deste estudo, o nariz estava localizado em plano nasal, dividido pela estrutura denominada filtro, com formato semipontudo, sendo a estrutura mais cranial da cabeça, com as narinas dispostas lateralmente em relação ao nariz (Fig.1A). 0 focinho da capivara era formado pelo ápice do nariz e a parte rostral da mandíbula e do maxilar. 0 nariz externo da capivara, no presente estudo, estava sustentado por um par de cartilagens e, internamente, a extremidade rostral do septo nasal formava a divisão entre os vestíbulos direito e esquerdo. A margem livre do septo oferecia fixação a outras cartilagens que sustentam as margens dorsal e lateral das narinas (Fig.1B,C). Internamente, nas capivaras analisadas, cada um dos vestíbulos nasais iniciava-se a partir de uma narina e chegavam até sua respectiva cavidade nasal, situada caudalmente ao nariz. Assim, a cavidade nasal também estava dividida em cavidade direita e esquerda. Esta divisão foi feita pelo septo nasal, que se encontrava com a superfície dorsal do palaro duro (Fig.1D). A maior parte da cavidade nasal da capivara estava ocupada pelas conchas nasais, que se apresentaram como estruturas em formato de espiral, com seus respectivos meatos.

\section{Laringe}

Em nosso estudo, laringe da capivara era um órgão muscular cartilaginoso, curto e de forma cônica, situada na parte ventral do pescoço, cranialmente à traqueia (Fig.2A). A laringe dos animais utilizados nesta pesquisa era formada por quatro cartilagens: a cartilagem cricóide, tireóide, aritenóide (com o processo cuneiforme e corniculado) e a cartilagem epiglote (Fig.2B-D). As cartilagens da laringe eram do tipo hialina e elástica (Fig.3), sendo que esta foi encontrada dentro da epiglote e nos processos corniculado e cu neiforme.

A cartilagem epiglótica das capivaras (Fig.2B) apresentou formato de folha, com base fixa na cartilagem tireoide e com sua margem livre pontiaguda. Essa cartilagem nas capivaras era composta por fibras do tipo elástica (Fig.3A). A cartilagem tireóidea era constituida por um corpo localizado numa porção ventral e duas lâminas dispostas lateralmente as quais possuiam formato retangular. Ela era composta por fibras do tipo hialina (Fig.3B). A cartilagem aritenoide, nos animais aqui estudados, possuia formato de concha e estava inserida na extremidade cranial da cricoide (Fig.2C). Possuia, também, dois processos: o processo corniculado (cranial) e o processo cuneiforme (caudal). A cartilagem aritenóide das capivaras utilizadas neste estudo era predominantemente hialina (Fig.3C). A cartilagem cricoide tinha a morfologia de um anel completo na extremidade caudal da laringe com uma lâmina dorsal expandida e um arco ventral mais estreito; em relação à composição da cartilagem era do tipo hialina (Fig.2D e 3D).

Conforme descrição de Junqueira \& Carneiro (2004), o epitélio respiratório reveste a maior parte da laringe. Apenas a superfície das cordas vocais e da epiglote são compostas por epitélio pavimentoso estratificado não queratinizado. Samuelson (2007) afirma que a lâmina própria submucosa da laringe é composta por tecido conjuntivo frouxo, abrigando células de defesa, tecido linfático difuso, nódulos linfáticos esparsos e glândulas mistas em algumas regiões (Fig.5C,D).

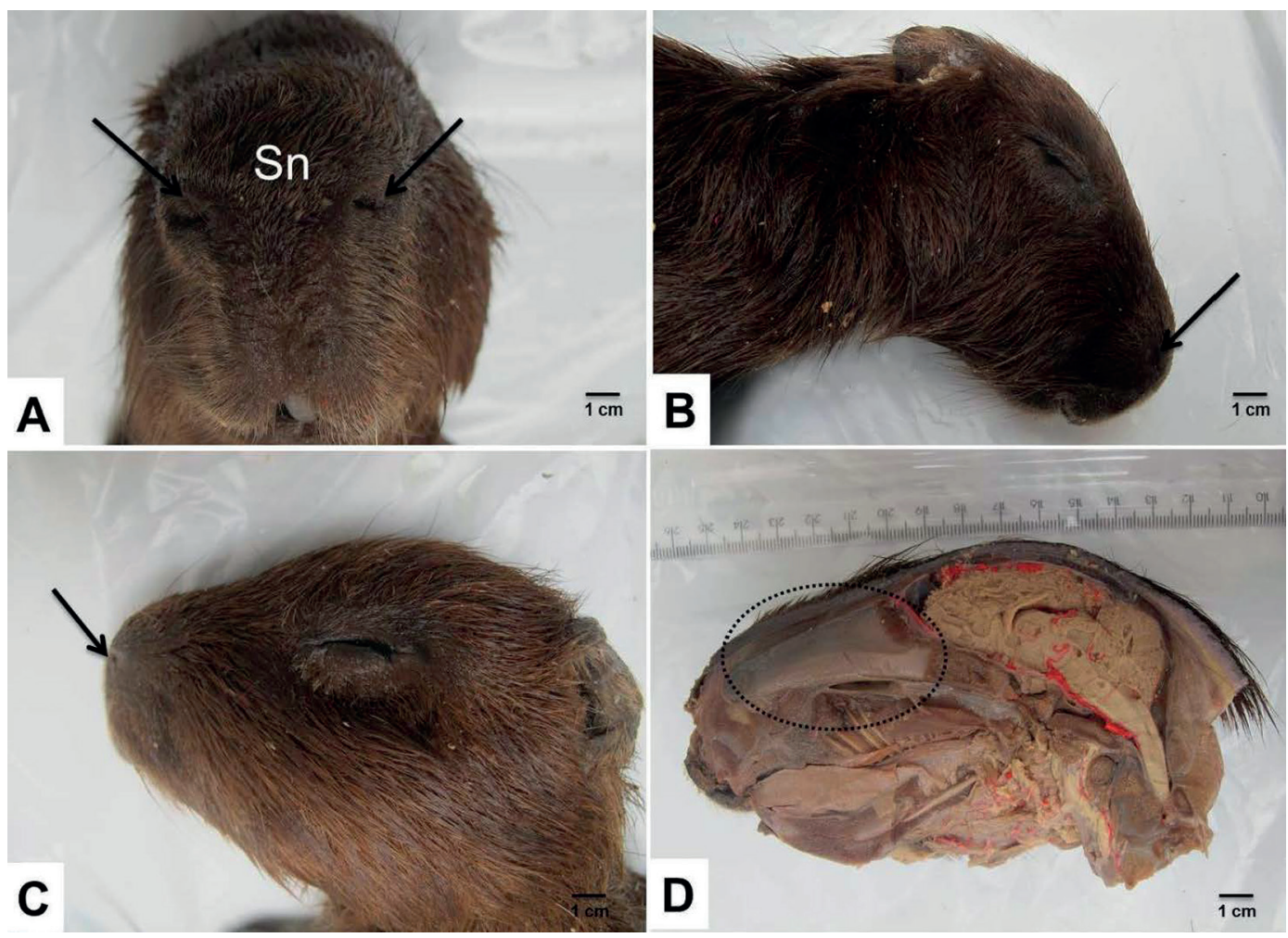

Fig.1. Nariz de capivara. (A-C) Narinas (seta) "in situ”, e plano nasal (Sn). (D) Cabeça seccionada medialmente; notar septo nasal (Circulo pontilhado). Técnica de dissecação. 

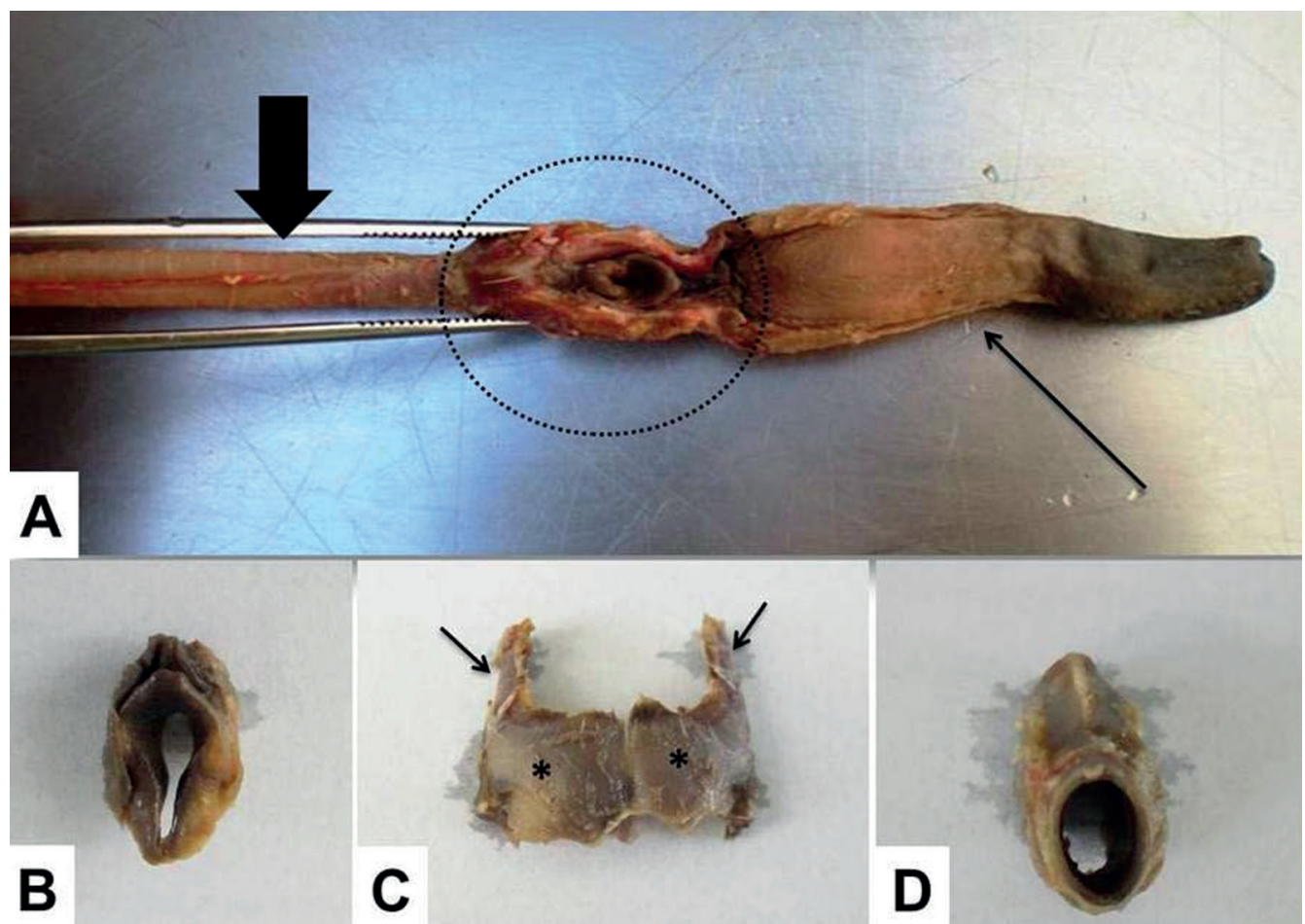

Fig.2. Laringe, traqueia e pulmão de capivara. (A) Traquéia (seta cheia), cartilagens da laringe ainda não dissecadas (circulo pontilhado) e língua (seta fina). (B) Cartilagem epiglote. (C) Cartilagens aritenóide (setas) e cartilagem tireóide (asterisco). (D) Cartilagem cricóide. Técnica de dissecação.

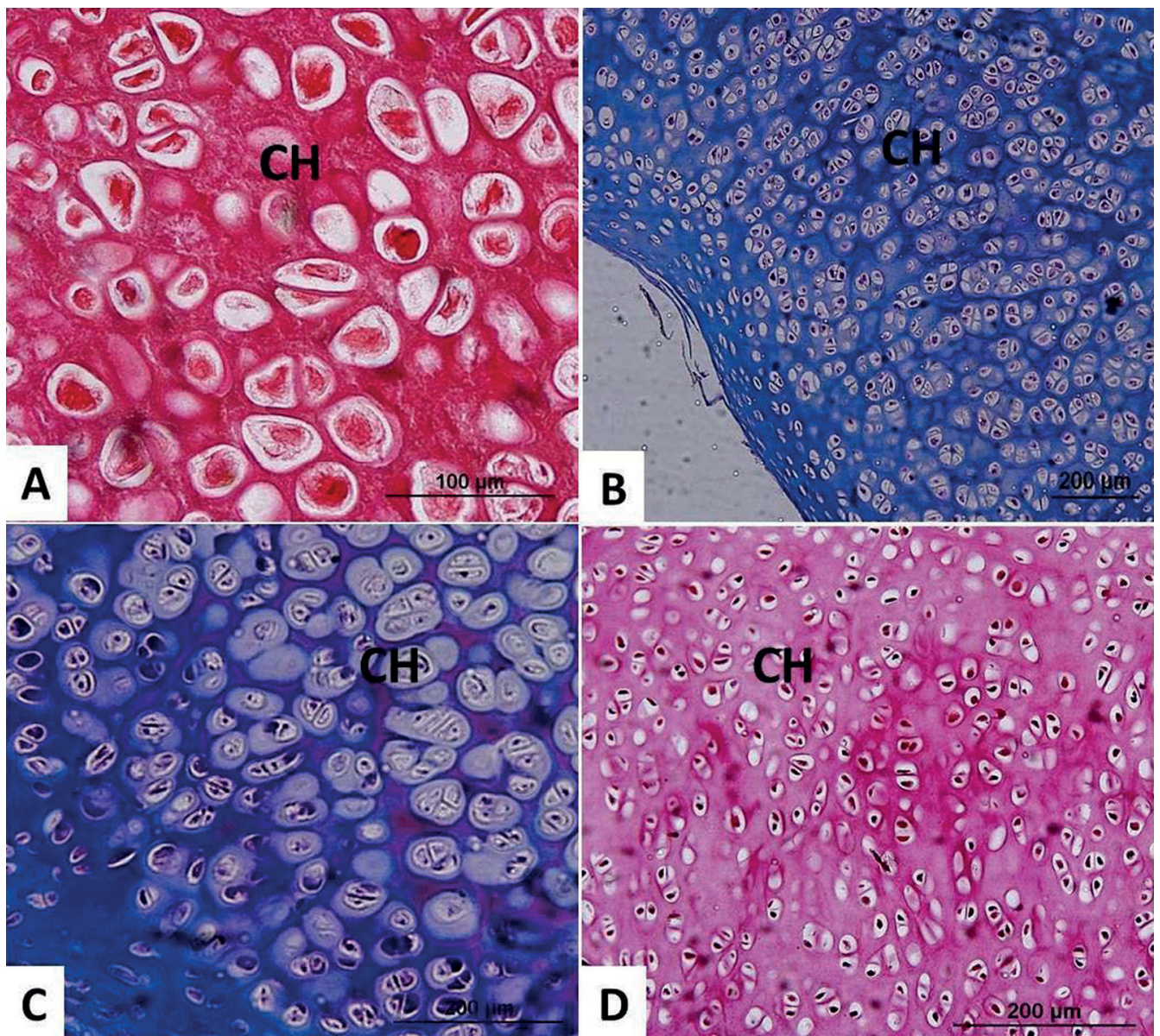

Fig.3. Cartilagens da laringe de capivara. (A) Cartilagem epiglótica. (B) Cartilagem tireóidea. (C) Cartilagem aritenóidea. (D) Cartilagem cricóidea. Coloração: (A/D) Picrossirius Red, (B/C) Tricômio de Masson. 

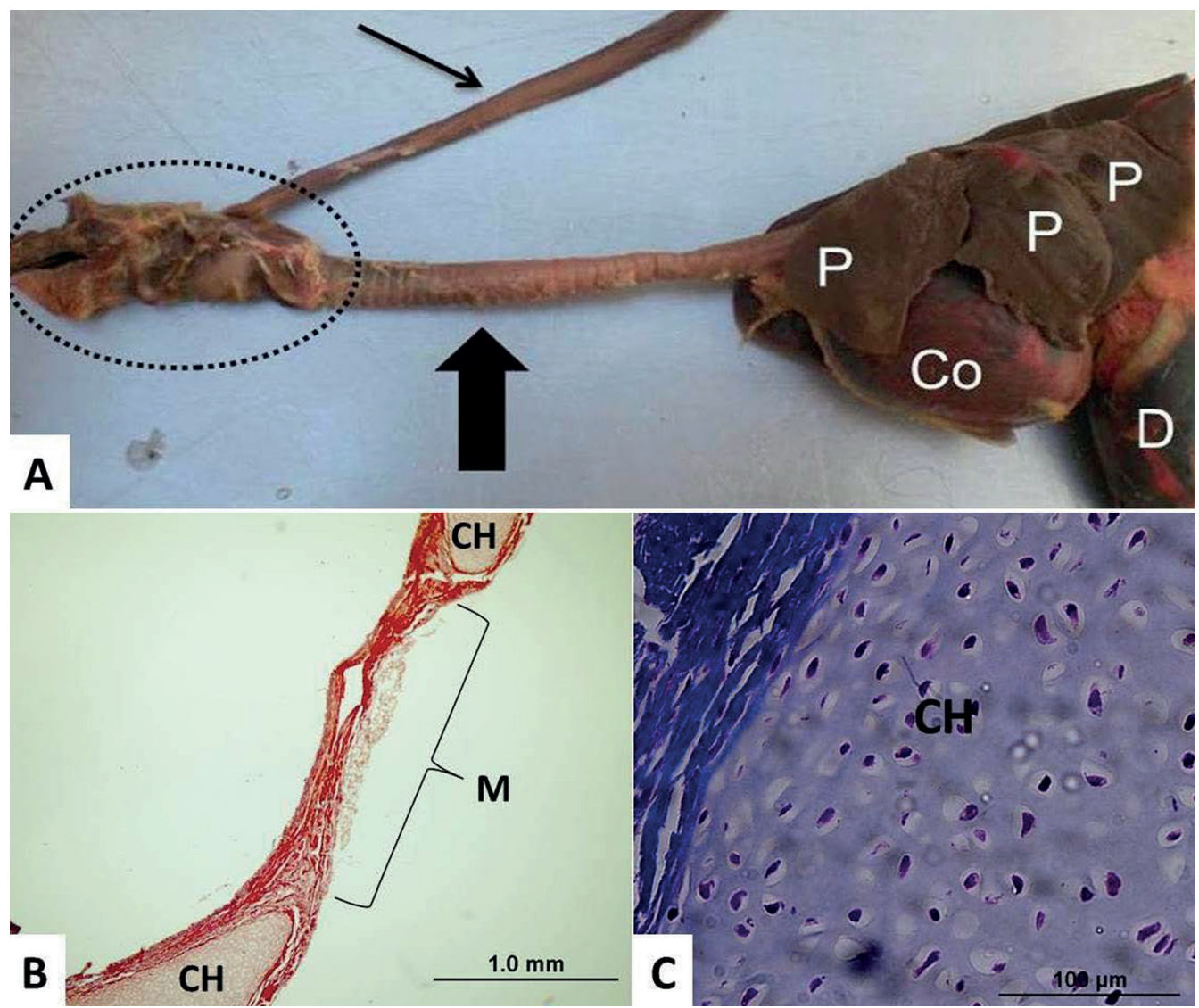

Fig.4. Laringe, taqueia e Pulmão de capivara. (A) Laringe (circulo pontilhado), esôfago (seta fina), traquéia (seta cheia), pulmão (P), coração (Co) e diafragma (D). (B,C) Traqueia. Cartilagem hialina (CH), músculo (M). Coloração: (B) Picrossirius Red, (C) Tricrômio de Masson.
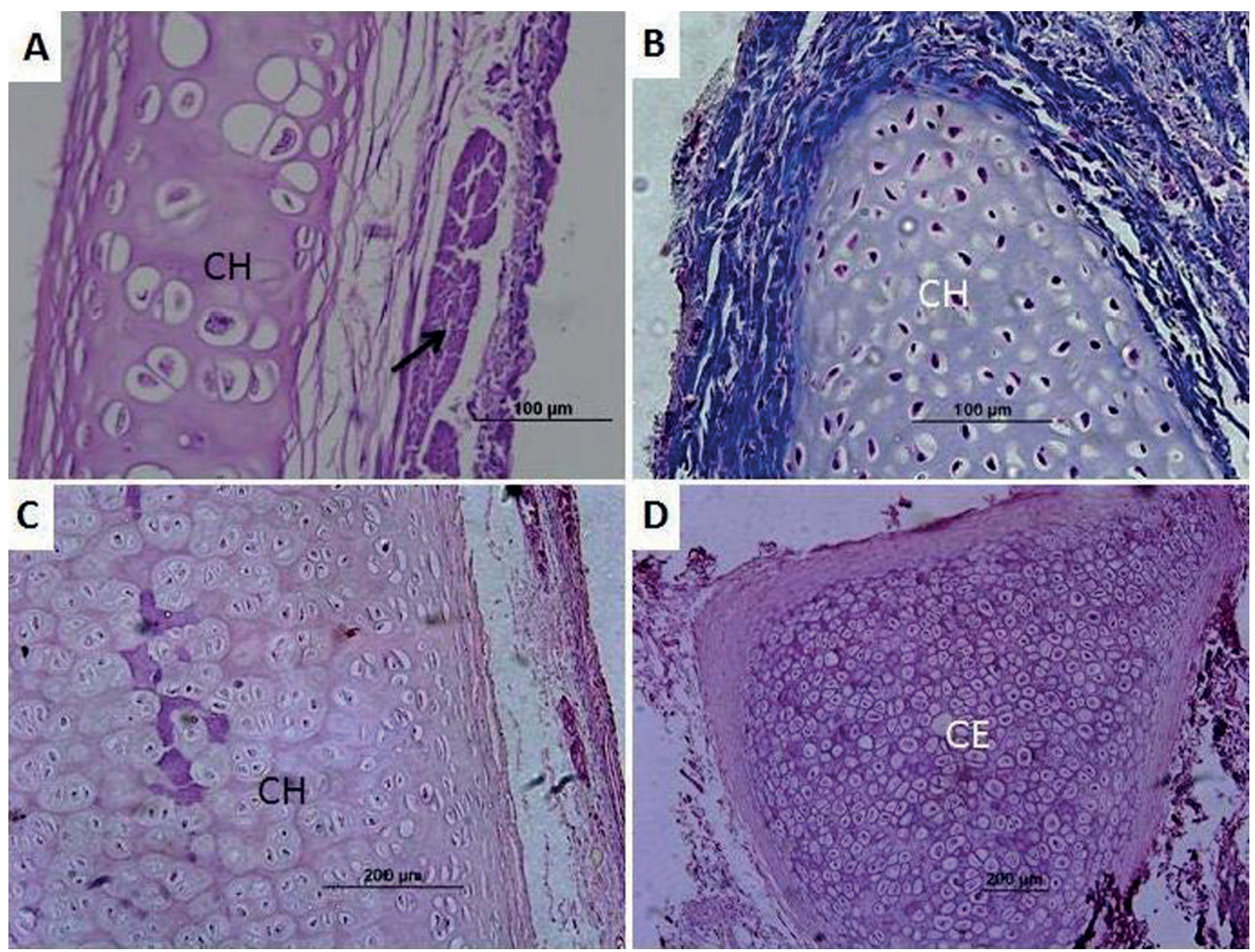

Fig.5. Traqueia e laringe de capivara. Notar a fragmentação do epitélio e de algumas camadas subepiteliais, não permitindo a correta identificação das mesmas. (A,B) Traqueia. (C) Cartilagem tireóidea da laringe. (D) Cartilagem epiglótica da laringe. Cartilagem hialina (CH), camada de musculatura lisa (seta). Coloração: (A,C,D) Hematoxilina-Eosina, (B) Tricrômio de Masson. 


\section{Traqueia}

Nas capivaras, a traqueia era um tubo que se prolongava desde a cartilagem cricoide da laringe, sendo formada por uma série de estruturas cartilaginosas em forma de " $\mathrm{C}$ ", conectadas por ligamentos (Figura 4). Foram encontrados, nas capivaras estudadas, 35, 43 e 46 anéis traqueais, sendo estes incompletos, com tecido muscular liso unindo as terminações destes anéis (Figura 4B). A face interna do tubo traqueal é revestida por epitélio respiratório. Abaixo do epitélio, na traqueia, encontrou-se uma lâmina própria e uma submucosa, que não estão claramente delimitadas devido à fragmentação do tecido. A estrutura da parede traqueal é formada por cartilagem hialina, seguida de uma camada de musculatura lisa, localizada dorsalmente na traqueia. Uma camada adventícia de tecido conjuntivo completa a formação da parede traqueal. A cartilagem hialina e a camada muscular (Fig.4B), puderam ser claramente identificadas na histologia realizada (Fig.4C e 5A,B).

\section{Árvore bronquica e pulmão}

Os pulmões encontrados nas capivaras deste estudo se apresentavam em número par, sendo um direito e um esquerdo, localizados na cavidade torácica. Cada pulmão estava revestido por uma membrana serosa, a pleura (Fig.7A), e dividido em lobos (Fig.6A,B) que se limitavam por profundas fissuras.

O pulmão direito apresentava quatro lobos (Fig.6A) (cranial, médio, caudal e acessório - estando este dividido em porção medial e lateral, através da fissura intralobar acessória). À delimitação entre os lobos cranial e médio damos o nome de incisura interlobar e, entre os lobos médio e caudal, de fissura interlobar.

0 pulmão esquerdo possuia dois lobos (Fig.6B), o lobo cranial e o lobo caudal, separados pela fissura interlobar. 0 cranial apresentava a incisura intralobar cranial, delimitando as porções cranial e caudal deste lobo; já o caudal não apresentava separação em porções. Na região torácica da capivara, a traqueia se bifurcava em sua parte terminal, formando a carina traqueal, dando origem aos brônquios extrapulmonares primários esquerdo e direito, chamados de brônquios primários. Esta bifurcação, e as subsequen-

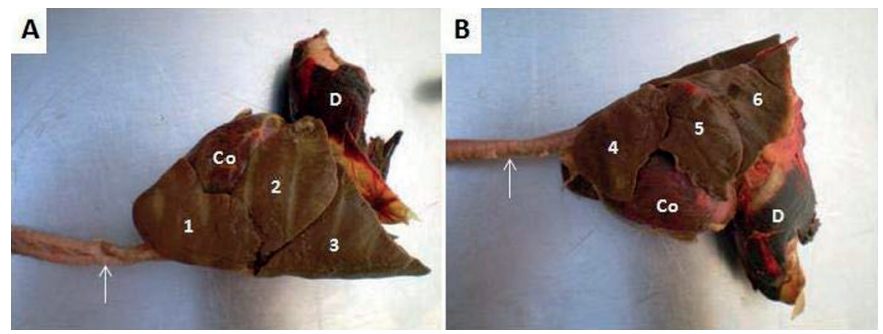

Fig.6. Vista lateral dos pulmões, coração (Co), diafrágma (D) e Tarqueia (Seta). (A) Pulmão direito, mostrando lobo cranial (1), médio (2) e caudal (2). Lobo acessório não pode ser visualizado. (B) Pulmão esquerdo, mostrando lobo cranial, porção cranial (4) , porção caudal (5), e lobo caudal (6). Técninca de dissecação.
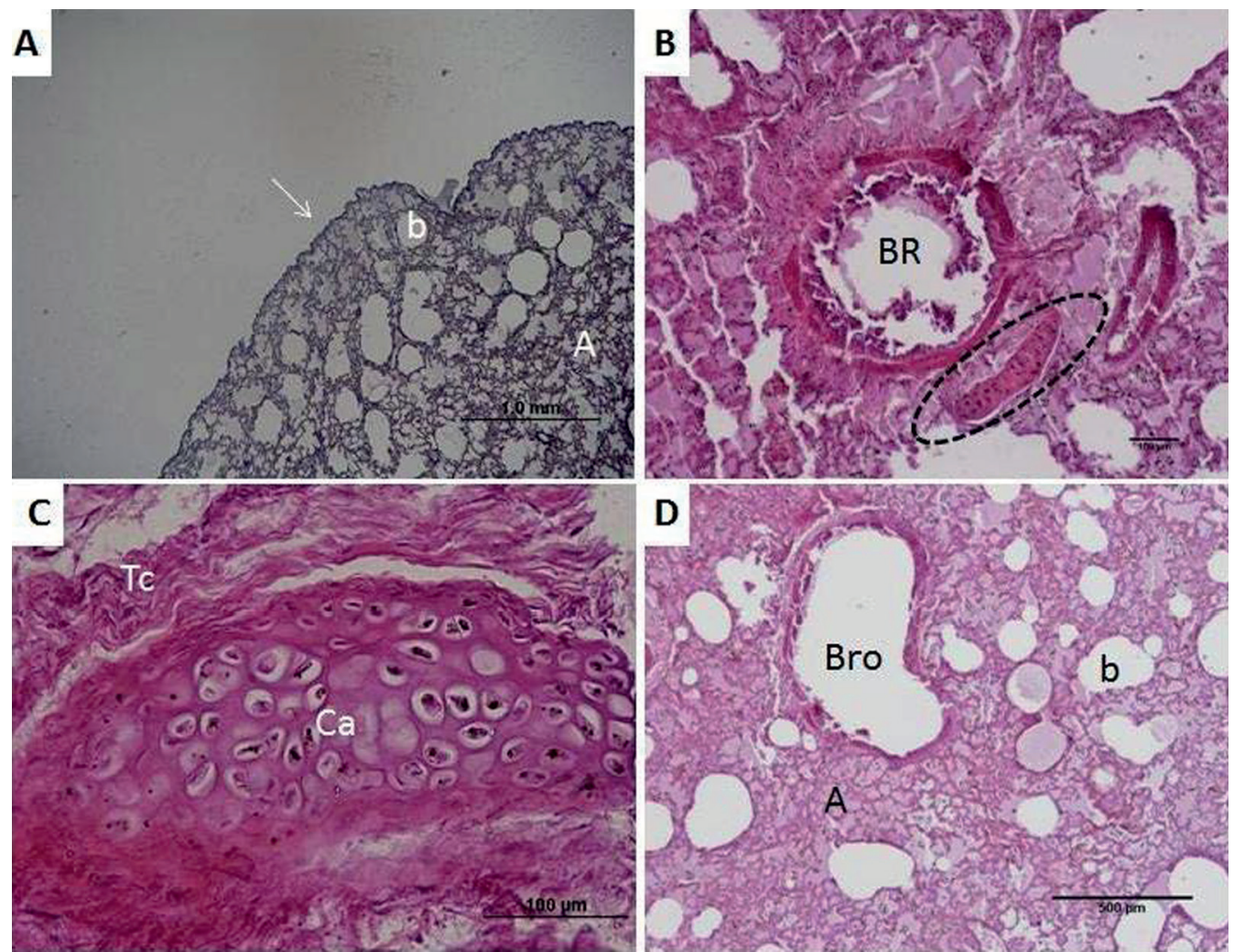

Fig.7. Pulmão de capivara. (A) Pleura (seta) e alvéolos (A). (B) Brônquio (BR) e cartilagem (elipse achurada). (C) Cartilagem (Ca) e tecido conjuntivo (Tc), em região de brônquio. (D) Bronquíolo (Bro) e alvéolos (A). Notar formações em forma de bolsões (b), indicativas de possível ruptura alveolar (em A e D) e importante framentação do tecido analisado (em B e C). Coloração: (B-D) Hematoxilina-Eosina, (A) Tricrômio de Masson. 
tes, deu origem as árvores bronquiais, que eram formadas pelo brônquio primário e por uma sequência intrapulmonar que incluiu brônquios intrapulmonares, bronquíolos, bronquíolos terminais e bronquíolos respiratórios. Esta divisão intrapulmonar originou, finalmente, os ductos e sacos alveolares.

A mucosa dos brônquios pareceu ser idêntica à da traqueia, enquanto nos ramos menores o epitélio era cilíndrico simples ciliado. Na região dos brônquios há peças cartilaginosas, envoltas por tecido conjuntivo. Estas são envolvidas por tecido conjuntivo rico em fibras elásticas. Os brônquios puderam ser identificados com facilidade, graças a presença das peças cartilaginosas (Fig.7B,C).

Os bronquíolos, ao contrário dos brônquios, não apresentaram cartilagem. 0 epitélio, nas porções iniciais, era cilíndrico simples, passando, na porção final, a cúbico simples. Além da observação do epitélio a identificação dos bronquíolos foi feita através da ausência de peças cartilaginosas (Fig.7C). Ainda, foi possível observar a presença de sacos alveolares contituidos por vários alvéolos, resultantes das sucessivas subdivisões da árvore bronquica (Fig.7A,D).

\section{DISCUSSÃO}

O aparelho respiratório, segundo Junqueira \& Carneiro (2004) é formado por uma porção condutora, que compreende as fossas nasais, nasofaringe, laringe, traqueia, brônquios e bronquíolos, e uma porção respiratória, onde ocorrem as trocas respiratórias, constituida pelos bronquíolos respiratórios, ductos alveolares e alvéolos. Segundo o mesmo autor, a maior parte da porção condutora é revestida por epitélio ciliado pseudo-estratificado colunar, com muitas células caliciformes, chamado epitélio respiratório.

O nariz, conforme descrito por Dyce et al. (2010), engloba o nariz externo, as cavidades nasais pares e os seios paranasais. Externamente, nossa descrição da forma do nariz está de acordo com com o descrito por König \& Liebich (2011) para outras espécies de mamíferos sendo uma estrutura cranial dividida pelo filtro com duas narinas dispostas lateralmente em cada antímero. A descrição das cartilagens nasais se apresenta conforme o relatado por esses autores para as demais espécies. Da mesma forma, a morfologia da cavidade nasal com suas conchas e meatos foi observada de acordo com a descrição desses autores e também como visto mais especificamente em camelos por Alsafy et al. (2014). Nos animais utilizados neste estudo, apenas as características macroscópicas das conchas e meatos nasais puderam ser analisadas.

A função da laringe segundo König \& Liebich (2011), é proteger a entrada da traqueia, impedindo a aspiração de corpos estranhos pelo trato respiratório inferior, além de ser importante para a vocalização. Assim como os demais mamíferos ela foi composta por cinco cartilagens, sendo que as principais variações ocorreram na forma.

A morfologia da cartilagem epiglótica das capivaras tinha sua margem livre pontiaguda, semelhante à descrição no cão e no cavalo, e diferente dos ruminantes e suínos, onde essa margem possui a forma arredondada ou ovalada (Hare 1981, Evans 1993, König \& Liebich 2011). Semelhante também às descrições feita por George et al. (1998) e Kerr (2000), nos mamíferos, e Aravenda et al. (2004), no cão e humano, a cartilagem epiglótica das capivaras era composta de cartilagem do tipo elástica. A cartilagem tireóidea, como descrito por Evans (1993); König \& Liebich (2011) e Hare (1981), forma as paredes laterais da laringe. No presente estudo, as lâminas, como no cão e diferentemente das do gato, apresentaram-se como placas aproximadamente retangulares. Segundo Dyce et al. (2010) a cartilagem tireoidea é do tipo hialina, assim como a encontrada nos animais deste estudo. A cartilagem aritenoide e cricoide não apresentaram variações consideráveis em sua morfologia sendo descritas de forma semelhante à encontrada em carnívoros (Hare 1981) e nos demais mamíferos (König \& Liebich 2011).

Segundo Hare (1981) o número de anéis traqueais é diverso nos mamíferos, variando de 29 a 60. Os equinos, bovinos, ovinos e caprinos possuem 48-60 anéis, suíno 2936, cão 42-46 e gato 38-43 anéis. Mesmo entre os roedores esse número varia. Em toupeiras, por exemplo, o número de aneis traqueais é, em média, de 29 (Ilgun et al. 2014), enquanto que, nas capivaras estudadas, foram encontrados 35 , 43 e 46 anéis, se assemelhando com o número encontrado nos felinos. Essa foi, portanto, a principal variação encontrada em relação à outros animais descritos na literatura.

Concordando com o descrito por Santos et al. (2011) nos quatis e Samuelson (2007), a disposição da traqueia e divisão da árvore bronquica segue o mesmo padrão como descrito para esses mamíferos. Apesar de haver descrição geral para os mamíferos é importante o reconhecimento dessas estruturas em animais silvestres como a capivara, uma vez que o conhecimento da morfologia se faz necessária para outras areas de atuação. Dentre essas se destaca hoje em dia a área de cirurgia em animais silvestres, um campo em constante crescimento na Medicina Veterinária (Minnich \& Mathisen 2007). A mucosa dos brônquios pareceu ser idêntica à da traqueia, enquanto nos ramos menores o epitélio era cilíndrico simples ciliado. Neste ponto ocorre uma pequena variação quanto ao encontrado na literatura. Cope et al. (2012) em sua pesquisa com marsupiais relata um epitélio cuboide a partir dos bronquios secundários se tornando um epitélio simples escamoso nos bronquíolos respiratórios. Quanto descrição da traqueia a disposição da cartilagem em forma de $\mathrm{C}$ unidas pelo músculo traqueal foi a mesma. Tais estudos sobre os tecidos traqueais e brônquicos se mostra importante uma vez que já foi relatada a presença de células-tronco no epitélio da mucosa e no ducto das glândulas traqueais (Brand-Saberi \& Schäfer 2014). A semelhança entre os tecidos e tipos celulares, pode ser um indicativo de fonte de células-tronco entre os animais silvestres.

Os pulmoes das capivaras apresentaram um padrão de lobação e disposição de fissuras semelhantes ao descrito por Oliveira et al. (2015) para catetos, Schwarze (1970) e Dyce et al. (2010) para o grupo dos mamíferos em geral e, especificamente, para capivaras descrito por Citrângulo et al. (2001). 0 padrão de pulmão direito dividido em quatro lobos e o esquerdo em dois diferiu apenas do descrito em toupeiras por Ilgun et al. (2014), nas quais o pulmão esquerdo não apresenta nenhuma divisão em lobos. 
Essas descrição comparadas se aplicam bem entre espécies de mamíferos de habitats e hábitos de vida semalhantes. Quando se compara nossas descrições à de espécies aquáticas ou de outras classes com aves, os contrastes são maiores. Por exemplo, Davenport et al. (2013) mostra achados diferentes da disposição dos órgãos do trato respiratório inicial em cetáceos, da mesma forma ocorrendo em aves galiformes descritas por Cevik-Demirkan et al. (2007). Em aves, além das características morfológicas do trato respiratório, foi descrito também a presença de tecido linfoide associado ao tecido respiratório (Kang et al. 2014). Essa associação de tecidos demonstra a versatilidade do trato respiratório quanto suas funções e pode ser investigada em mamíferos também. Logo, percebe-se que a anatomia desses órgãos é condizente com a função adaptada aos hábitos e habitats naturais das espécies.

\section{CONCLUSÕES}

0 aparelho respiratório da capivara é formado pelas narinas, fossas nasais, cavidade nasal, seios paranasais, faringe, laringe, traqueia e pulmões.

O nariz fica localizado em plano nasal, com formato semipontudo e voltado para frente, com as narinas dispostas lateralmente.

A maior parte da cavidade nasal da capivara é ocupada pelas conchas nasais, que se apresentaram como estruturas em formato de espiral, com seus respectivos meatos.

A laringe é um órgão muscular cartilaginoso, curto, de forma cônica, que está em comunicação com a traqueia.

A traqueia é um tubo cartilaginoso flexível e membranoso, com anéis incompletos em formato de " $\mathrm{C}$ ", que se inicia no final da laringe e, região torácica, se bifurcava em sua parte terminal, formando a carina traqueal.

Os pulmões das capivaras são em pares, direito (com quatro lobos) e esquerdo (com dois lobos), localizados na cavidade torácica.

As árvores brônquicas da capivara são formadas pelo brônquio primário e por uma sequência intrapulmonar que inclui brônquios intrapulmonares, bronquíolos, bronquíolos terminais e bronquíolos respiratórios.

Agradecimentos.- À Fundação de Amparo à Pesquisa do Estado de São Paulo-FAPESP, pelo apoio financeiro para publicação desta pesquisa (Processo FAPESP 2012/01934-4).

\section{REFERÊNCIAS}

Alsafy M.A.M., El-Gendy S.A.A. \& Abumandour M.M.A. 2014. Computed tomography and gross anatomical studies on the head of one-humped camel (Camelus dromedarius). Anat. Rec. 297:630-642.

Aravenda L.D., Rico B., Flores E. \& Cattaneo G. 2004. Laringe canina y humana: un estudo para estabelecer homologia. Arqs Ciênc. Vet. Zoologia Unipar 7:135-139.

Arouca M.E., Miranda L.B., Lopes R.S., Takahira R.K., Kohayagawa A., Ciarlini P. \& Oba E. 2000. Valores hematológicos de capivaras (Hydrochoerus hydrochaeris) criadas em cativeiro no município de Botucatu, SP. Ciência Rural 30:813-817.

Brand-Saberi B.E.M. \& Schäfer T. 2014. Trachea: anatomy and phisiology. Thorac. Surg. Clin 24:1-5.

Bonatelli M., Machado M.R.F., Cruz C. \& Miglino M.A. 2001. Análise morfológica da placenta da paca (Agouti paca, Linneaus, 1766). Estudo ao microscópio de luz e à microscopia eletrônica de transmissão. Braz. J. Vet. Res. Anim. Sci. 38:224-228.

Bressan M.C., Jardim N.S., Perez J.R.O., Thomazini R., Lemos A.L.S.C., Oda S.H.I., Pisa R.C.C., Vieira J.O., Faria P.B. \& Freitas R.T.F. 2004. Influência do sexo e faixas de peso ao abate nas características fisico-químicas da carne de capivara. Ciênc. Tecnol. Alimentos 24:357-362.

Cevik-Demirkan A., Haziroglu R.M. \& Kürtül I. 2007. Gross morphological and histological features of larynx, trachea, and syrinx in Japanese quail. Anat. Histol. Embryol. 36: 215-219.

Citrângulo M., Ribeiro A.A.C.M., Moraes P.T.B. \& Machado M.R.F. 2001. Lobação e vascularização arterial do pulmão da capivara (Hydrochaeris hydrochaeris). Arq. Ciênc. Vet. Zoologia Unipar 4:119-127.

Conceição R.A., Ambrósio C.E., Martins D.S., Carvalho A.F., Franciolli A.L.R., Machado M.R.F., Oliveira M.F. \& Miglino M.A. 2008. Aspectos morfológicos do saco vitelino em roedores da subordem Hystricomorpha: paca (Agouti paca) e cutia (Dasyprocta aguti). Pesq. Vet. Bras. 28:253-259.

Cope L.A., Henry R.W. \& Reed Jr R.B. 2012. Microscopic anatomy of the lower repiratory tract of the grey short-tailed opossum (Monodelphis domestica). Anat. Histol. Embryol. 41:96-105.

Davenport J., Cotter L., Rogan E., Kelliher D. \& Murphy C. 2013. Structure, material characteristics and function of upper respiratory tract in pygmy sperm whale. J. Exp. Biol. 216:4639-4646.

Dyce K.M., Sack W.O. \& Wensing C.J.G. 2010. Tratado de Anatomia Veterinária. 4⿳亠丷a ed. Elsevier Editora, Rio de Janeiro. 834p.

Evans H.E. 1993. Anatomy of the Dog. W.B. Saunders, Philadelphia, p.487492.

Fernandez D.S., Ferraz R.H.S, Melo A.P.F., Rodrigues R.F. \& Souza W.M. 2010. Análise histológica das glândulas uretrais da capivara (Hydrochoerus hydrochaeris). Pesq. Vet. Bras. 30:373-377.

Franciolli A.L.R., Ambrósio C.E., Oliveira M.F., Morini A.C., Favaron P.O., Machado M.R.F. \& Miglino M.A. 2011. Os histricomorfos sul-americanos: uma análise comparativa do desenvolvimento embriológico. Pesq. Vet. Bras. 31:441-446.

George L.L., Alves C.E.R. \& Castro R.R.L. 1998. Histologia Comparada. $2^{\underline{a}}$ ed. Roca, São Paulo. 286p.

Hare W.C.D. 1981. Sistema Respiratório, p.108-135. In: Getty R. (Ed.), Anatomia dos Animais Domésticos. 5a ed. Guanabara Koogan, Rio de Janeiro.

Ilgun R., Yoldas A., Kuru N. \& Özkan Z.E. 2014. Macroscopy anatomy of the lower respiratory system in mole rats (Spalax leucodon). Anat. Histol. Embryol. 43:474-481.

International Committee on Veterinary Gross Anatomical Nomenclature 2012. Nomina Anatomica Veterinaria. $5^{\underline{a}}$ ed. Editorial Committee, Hannover, Columbia, Ghent, Sapporo.

Junqueira L.C. \& Carneiro J. 2004. Histologia Básica. 10aㅡ ed. Guanabara Koogan, Rio de Janeiro.

Kang H., Yan M., Yu Q. \& Yang Q. 2014. Characterization of nasal cavity-associated lymphoid tissue in ducks. Anat. Rec. 297:916-924.

Kerr J.B. 2000. Atlas de Histologia Funcional. Artes Médicas, São Paulo. 40p.

König H.E. \& Liebich H.G. 2011. Anatomia dos Animais Domésticos: texto e atlas colorido. $4^{\mathrm{a}} \mathrm{ed}$. Artmed, Porto Alegre.

Luckett W.P. \& Mossman H.W. 1981. Development and phylogenetic significance of the fetal membranes and placenta of the African hytricognathous rodents Bathyergus and Hystrix. American J. Anat. 162:265285.

Menezes D.J.A., Carvalho M.A.M., Cavalcante Filho M.F. \& Souza W.M. 2001. Configuração do sistema venoso portal na cutia (Dasypocta agouti, Rodentia). Braz. J. Vet. Res. Anim. Sci. 38:263-266.

Minnich D.J. \& Mathisen D.J. 2007. Anatomy of the trachea, carina, and bronchi. Thorac. Surg. Clin. 17:571-585.

Moojen J. 1962. Os Roedores do Brasil. Instituto Nacional do Livro, Ministério de Educação e Saúde, Rio de Janeiro. 214p.

Oliveira G.B., Oliveira R.E.M., Bezerra F.V.F. \& Oliveira M.F. 2015. Lobação, árvore brônquica e vascularização do pulmão de catetos (Pecari tajacu Linnaeus, 1758). Caatinga 28:247-255. 
Pereira H. \& Eston M.R. 2007. Biologia e manejo de capivaras (Hydrochoerus hydrochaeris) no Parque Estadual Alberto Löfgren, São Paulo, Brasil. Revta Inst. Florestal 19:55-64.

Reckziegel S.H., Lindemann T. \& Campos R. 2001. A systematic study of the brain base arteries in capybara (Hydrochoerus hydrochaeris). Braz. J. Morphol. Sci. 18:103-110.

Reig O.A. 1984. Distribuição geográfica e história evolutiva dos roedores muroideos sul-americanos (Cricetidae: Sigmodontidae). Revta. Bras. Genet. 7:333-365
Samuelson D.A. 2007. Tratado de Histologia Veterinária. Elsevier, Rio de Janeiro.

Santos A.C., Bertassoli B.M., Oliveira V.C., Souza A.F., Rosa R.A., Carvalho A.F. \& Mançanares C.A.F. 2011. Morfologia da árvore brônquica de pulmões de quatis (Nasua nasua Linnaeus, 1966). Biotemas 24:75-82.

Schwarze E. 1970. Compendio de Anatomia Veterinária. Acribia, Zaragoza.

Tolosa E.M.C., Rodrigues C.J. \& Behmer O.A. 2003. Manual de Técnicas para Histologia Normal e Patológica. $2^{a}$ ed. Manole, São Paulo. 331p. 